\title{
Characterization of Dominant-Negative Forms of Anthrax Protective Antigen
}

\author{
Ming Yan AND R John COLlier
}

Certain mutations within the protective antigen (PA) moiety of anthrax toxin endow the protein with a dominant-negative (DN) phenotype, converting it into a potent antitoxin. Proteolytically activated PA oligomerizes to form ring-shaped heptameric complexes that insert into the membrane of an acidic intracellular compartment and promote translocation of bound edema factor and/or lethal factor to the cytosol. DN forms of PA co-oligomerize with the wild-type protein and block the translocation process. We prepared and characterized $4 \mathrm{DN}$ forms: a single, a double, a triple, and a quadruple mutant. The mutants were made by site-directed mutation of the cloned form of PA in Escherichia coli and tested by various assays conducted on $\mathrm{CHO}$ cells or in solution. All 4 mutant PAs were competent for heptamerization and ligand binding but were defective in the pH-dependent functions: pore formation, ability to convert to the SDS-resistant heptamer, and ability to translocate bound ligand. The single mutant (F427K) showed less attenuation than the others in the pH-dependent functions

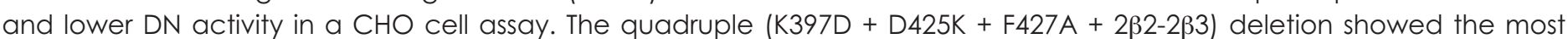
potent DN activity at low concentrations but also gave indications of low stability in a urea-mediated unfolding assay. The double mutant (K397D + D425K) and the triple (K397D + D425K + F427A) showed strong DN activity and slight reduction in stability relative to the wild-type protein. The properties of the double and the triple mutants make these forms worthy of testing in vivo as a new type of antitoxic agent for treatment of anthrax.

\section{INTRODUCTION}

The major symptoms of anthrax are believed to result from the effects of a tripartite toxin secreted by the anthrax bacillus, Bacillus anthracis. Anthrax toxin consists of 3 large proteins that assemble at the surface of receptor-bearing mammalian cells to form toxic, noncovalent complexes $(1,2)$. Two of the proteins, lethal factor (LF) and edema factor (EF), are enzymes that covalently modify substrates within the cytosolic compartment. The 3rd, protective antigen (PA), serves to bind LF and EF to the cell and mediate their entry into the cytosol.

Our current working model of assembly and entry of the toxic complexes is as follows: Assembly begins when PA binds to a cellsurface receptor and is cleaved into 2 fragments by a member of the furin family of cell-associated proteases $(3,4)$. Trypsin cleaves PA preferentially at the furin site and may be used to activate the protein in solution. The smaller, N-terminal fragment $\left(\mathrm{PA}_{20}\right.$, $20 \mathrm{kDa}$ ) dissociates into the medium, leaving the complementary fragment $\left(\mathrm{PA}_{63}, 63 \mathrm{kDa}\right)$ bound to the receptor. Removal of $\mathrm{PA}_{20}$ relieves a steric barrier to oligomerization of $\mathrm{PA}_{63}$ and to its binding of EF and LF (5). $\mathrm{PA}_{63}$ self-associates to form 7-membered, ring-shaped oligomers (6), and these heptamers bind EF and LF competitively. The resulting hetero-oligomers, containing up to 3 molecules of EF and/or LF per $\mathrm{PA}_{63}$ heptamer, are endocytosed and trafficked to an acidic compartment within the cell (7). There, the low $\mathrm{pH}$ promotes a conformational change in the $\mathrm{PA}_{63}$ heptamer that allows it to insert into the membrane and form a pore (8). Concurrently EF and LF translocate across the membrane to the cytosol. EF catalyzes conversion of ATP to cAMP (9), and LF proteolytically attacks certain MAP kinase kinases and perhaps other cytosolic proteins $(10,11)$.

Clues to the conformational change involved in conversion of the preinsertion form of the $\mathrm{PA}_{63}$ heptamer (termed the prepore) to the pore form came from the crystallographic structures of the prepore and of intact PA (5). A disordered loop $\left(2 \beta_{2}-2 \beta_{3}\right)$ of the poreforming domain (domain 2) showed sequence characteristics consistent with the formation of a transmembrane, amphipathic $\beta$-barrel (similar to that of the Staphylococcal $\alpha$-toxin). Evidence to support this model came from electrophysiological measurements on PA mutants containing Cys-substitutions within the $2 \beta_{2}-2 \beta_{3}$ loop (12). The loop in the prepore is located in the midsection of domain 2 as part of a Greek key motif. It was proposed that for the transmembrane $\beta$-barrel to form, the $2 \beta$ strands flanking the loop must be stripped out from the body of the domain, allowing the loop to relocate to the base of the structure. Clearly this implies a major conformational change in the domain. Consistent with this notion, the prepore becomes resistant to dissociation by sodium dodecyl sulfate (SDS) as it converts to the pore conformation (6).

Recently we reported that mutation of 3 residues in 2 loops on the opposite (luminal) face of domain 2 blocked the ability of PA to mediate translocation of bound ligands (13). Also, deletion of the $2 \beta_{2}-2 \beta_{3}$ loop blocked both pore formation and translocation, as predicted by the $\beta$-barrel model (14). Later experiments showed that some of these mutations, or combinations of them, endowed PA with a dominant-negative (DN) phenotype (15). When mixed with wild-type PA, the DN-PAs strongly inhibited translocation both in vitro and in vivo. Among the mutants tested, a double, K397D + D425K, was found have the most potent dominant-negative

Department of Microbiology and Molecular Genetics, Harvard Medical School, 200 Longwood Avenue, Boston, MA 02115. 
activity. Also, a mutant PA in which residues of the $2 \beta_{2}-2 \beta_{3}$ loop were replaced with a corresponding region of the PA homolog from iota toxin of Clostridium perfringens was reported to have similar properties (16). We believe the various dominant-negative mutations in some way block the conformational change in domain 2 required for conversion of the prepore to the pore.

These findings raised the possibility that DN-PAs might represent a novel approach to therapy of anthrax. In the current study we have examined the characteristics of a selected set of DN-PAs that are candidates for further testing in animals as novel antitoxins. The double, K397D + D425K, mutant was used as the primary template to analyze the effects of additional mutations.

\section{MATERIALS AND METHODS}

\section{Cell Culture, Media, and Chemicals}

Chinese Hamster Ovary-K1 (CHO-K1) cells were obtained from the American Type Culture Collection. Cells were grown in Ham's F-12 medium supplemented with 10\% calf serum, $2 \mathrm{mM}$ glutamine, 500 units/mL penicillin, and 500 units/mL streptomycin sulfate and maintained at $5 \% \mathrm{CO}_{2}$ in a humidified atmosphere. All supplies for the cell culture were from Invitrogen Technologies, unless noted otherwise. All chemicals were obtained from Sigma Chemical Co, unless specified.

\section{Preparation of PA Proteins}

Mutations were constructed following the QuickChange (Stratagene Inc) method of site-directed mutagenesis. Mutations were cloned into the expression vector pET22b(+), transformed into E. coli (XL-1 Blue) by electroporation. Mutagenesis was confirmed by sequencing. Proteins were expressed in E. coli (BL21 $D E 3)$ by induction with $1 \mathrm{mM}$ IPTG at $30^{\circ} \mathrm{C}$ for $3 \mathrm{~h}$. Cells from a 2.5 - $\mathrm{L}$ culture were harvested by centrifugation at $8000 \times \mathrm{g}$, resuspended in $500 \mathrm{~mL} 20 \mathrm{mM}$ Tris, $\mathrm{pH}$ 8.0, 20\% sucrose, and $1 \mathrm{mM}$ EDTA, and stirred at $4{ }^{\circ} \mathrm{C}$ for $15 \mathrm{~min}$. After recentrifugation at $8000 \times g$, cells were resuspended in $500 \mathrm{~mL}$ ice-cold $5 \mathrm{mM}$ $\mathrm{MgSO}_{4}$ and stirred at $4{ }^{\circ} \mathrm{C}$ for $15 \mathrm{~min}$. The periplasmic shock extract was obtained by decanting after centrifugation at $10000 \times g$ at $4{ }^{\circ} \mathrm{C}$ for $15 \mathrm{~min}$. The periplasmic shock extract then was loaded onto a Q-Sepharose column. After equilibration with Buffer A (20 mM Tris, pH 8.0), proteins were eluted with a linear gradient of $0 \%$ to $35 \%$ Buffer $\mathrm{B}(20 \mathrm{mM}$ Tris $\mathrm{pH} 8.0,1 \mathrm{M} \mathrm{NaCl})$. The collected fractions were monitored by $11.25 \%$ SDS-PAGE, and those containing PA at more than $90 \%$ purity were pooled and stored at $-80{ }^{\circ} \mathrm{C}$. Protein concentration was determined by the Bradford assay (Bio-Rad Laboratories).

\section{Binding and Translocation of the N-terminal Domain of LF (LFn) on the Cell Surface}

Preseeded CHO-K1 $\left(2.5 \times 10^{5} / \mathrm{mL}\right)$ cells were chilled on ice for $15 \mathrm{~min}$. Then $1 \mu \mathrm{g}$ per well trypsin-nicked PA in $250 \mu \mathrm{L}$ ice-cold F-12-HEPES, pH 8.0, was added. After incubation on ice for $1 \mathrm{~h}$, $250 \mu \mathrm{l}\left[{ }^{35} \mathrm{~S}\right]-\mathrm{LFn}$, produced in an in vitro transcription-translation system using TNT Coupled Reticulocyte Lysate system (Promega Inc), dissolved in ice-cold F-12, and buffered with 20 mM HEPES, $\mathrm{pH} 8.0$, was added. Then the cells were incubated on ice for $1 \mathrm{~h}$.
The unbound [ $\left.{ }^{35} \mathrm{~S}\right]-\mathrm{LF}$ was removed by aspiration, and $\left[{ }^{35} \mathrm{~S}\right]-\mathrm{LFn}$ translocation was triggered by treatment of $250 \mu \mathrm{l}$ translocation buffer (140 mM NaCl, $20 \mathrm{mM}$ 2-[N-morpholino] ethanesulfonic acid (MES) $5 \mathrm{mM}$ gluconic acid, $\mathrm{pH} 4.8$ ) at $37{ }^{\circ} \mathrm{C}$ for $1 \mathrm{~min}$. Pronase ( $1 \mathrm{mg} /$ well in F-12-HEPES, pH 8.0) was added into some wells to remove LFn bound on cell surface after translocation. Cells treated with or without protease were lysed in $250 \mu \mathrm{L}$ lysis buffer (20 mM sodium phosphate, pH 7.4, 10 mM EDTA, 1\% Triton $\mathrm{X}-100)$. Samples were counted in a scintillation counter. The efficiency of translocation was calculated as dpm protected from protease/dpm total [ $\left.{ }^{35} \mathrm{~S}\right] \mathrm{LFn}$ bound on cell surface.

\section{Pore Formation on the Cell Surface}

$\mathrm{CHO}-\mathrm{K} 1$ cells were seeded at a density of $1.5 \times 10^{5} / \mathrm{mL}$ in 24 well plates and incubated at $37{ }^{\circ} \mathrm{C}$ overnight. The medium was removed and replaced with fresh F-12 medium containing $1 \mu \mathrm{Ci} / \mathrm{mL}^{86} \mathrm{Rb}$ (NEN Inc) and incubated overnight. Cells were chilled on ice for $15 \mathrm{~min}$ and washed with chilled phosphatebuffered saline (PBS) followed by addition of $1 \mu \mathrm{g}$ trypsin nicked PA in $250 \mu \mathrm{L}$ F-12-HEPES buffer, $\mathrm{pH}$ 8.0. After incubation on ice for $1 \mathrm{~h}$, cells were washed with ice-cold PBS, followed by addition of $\mathrm{pH} 4.8$ or $\mathrm{pH} 8.0$ buffer $(140 \mathrm{mM} \mathrm{NaCl}, 20 \mathrm{mM}$ MES, $5 \mathrm{mM}$ gluconic acid, $\mathrm{pH} 4.8$ or $\mathrm{pH} 8.0)$. After 15 min incubation, supernatant containing released ${ }^{86} \mathrm{Rb}$ was collected and counted in a gamma-counter.

\section{$\left(\mathrm{PA}_{63}\right)_{7}$-LFn Complex Formation}

Mutant or wild type (WT)-PA (6 $\mu$ g protein) were treated with 6 $\mathrm{ng}$ trypsin at room temperature for $30 \mathrm{~min}$ followed by $60 \mathrm{ng}$ trypsin inhibitor at room temperature for $15 \mathrm{~min}$. Trypsin-nicked PA was incubated with an equimolar amount of LFn at room temperature for $2 \mathrm{~h}$. After incubation, samples were loaded onto $4 \%$ to $20 \%$ native gradient gels (BioWhittaker Molecular Applications Inc). After electrophoresis, proteins were visualized by Coomassie Brilliant Blue staining.

\section{SDS-resistant Heptamer Formation}

Trypsin-nicked PA $(6 \mu \mathrm{g})$ was incubated with an equimolar amount of LFn at room temperature for $2 \mathrm{~h}$. Formation of SDSresistant heptamer was triggered by adding $100 \mathrm{mM}$ sodium acetate $\mathrm{pH} 4.0$ until the $\mathrm{pH}$ reached 5.0. After incubation at room temperature for $30 \mathrm{~min}$, samples were dissolved in SDS-PAGE sample buffer and run on a $4 \%$ to $20 \%$ gradient SDS-PAGE (BioWhittaker Molecular Applications Inc). Proteins were visualized by Coomassie Brilliant Blue staining.

\section{Dominant-Negative Inhibition Assay}

A mixture of various amounts of DN mutants with a constant amount of WT-PA $\left(2 \times 10^{-10} \mathrm{M}\right)$ and LFn-DTA $\left(1 \times 10^{-9} \mathrm{M}\right)$ was added into 96-well plates previously seeded with $\mathrm{CHO}-\mathrm{K} 1$ cells $\left(2.5 \times 10^{5}\right.$ cells/well). DTA is the catalytic domain of diphtheria toxin. After incubation at $37^{\circ} \mathrm{C}$ for $4 \mathrm{~h}$, the medium containing PA and LFn-DTA was removed and replaced with leucine-free F-12 medium supplemented with $1 \mu \mathrm{Ci} / \mathrm{mL}\left[{ }^{3} \mathrm{H}\right]$-leucine (NEN Inc). After incubation with $\mathrm{CHO}-\mathrm{K} 1$ cells at $37^{\circ} \mathrm{C}$ for $1 \mathrm{~h}$, the efficiency of inhibiting PA-dependent cell killing was monitored by measuring the quantity of $\left[{ }^{3} \mathrm{H}\right]$-leucine incorporated. 


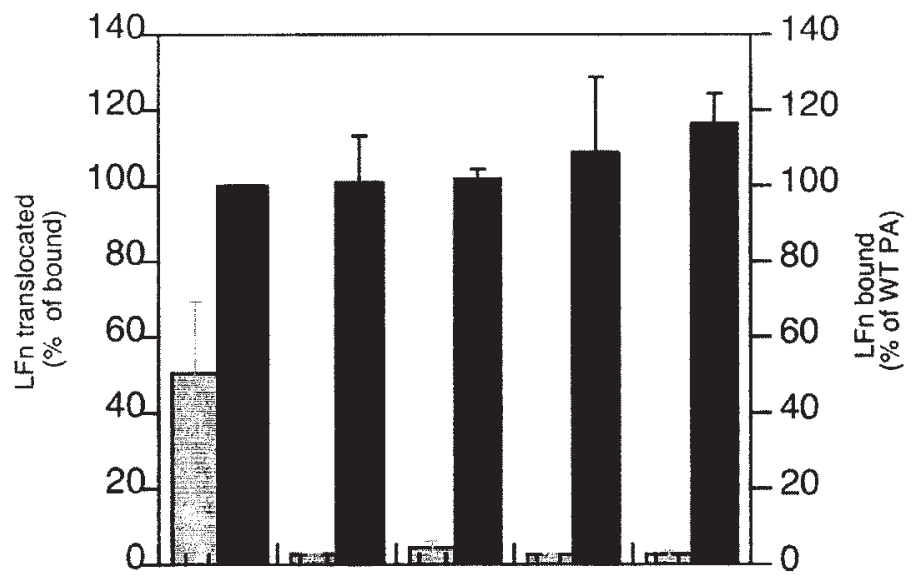

WT Double Triple Quadruple F427K

Figure 1. LFn binding and translocation by $\mathrm{DN}$ mutants. $\mathrm{CHO}-\mathrm{K} 1$ cells were incubated with trypsin-nicked PA $\left(5 \times 10^{-8} \mathrm{M}\right)$ on ice for $1 \mathrm{~h}$, then washed and incubated with [ $\left.{ }^{35} \mathrm{~S}\right]-\mathrm{LFn}$ for an additional hour. After washing with ice-cold PBS, half of each sample of cells was lysed, and [ $\left.{ }^{35} \mathrm{~S}\right]-$ LFn bound was measured by scintillation counting. The other half was incubated with $\mathrm{pH} 4.8$ buffer at $37^{\circ} \mathrm{C}$ for 1 min to trigger translocation, and protease was then added to digest untranslocated LFn on cell surface. Cells were then washed and lysed, and [ $\left.{ }^{35} \mathrm{~S}\right]-\mathrm{LFn}$ translocated into the cytosol was measured by scintillation counting. $\mathbf{n}$, cell-surface bound [35S]-LFn $(\times 100) . \square$, percentage of bound LFn translocated.

\section{Intrinsic Fluorescence of DN PA in Urea}

PA (50 $\mu \mathrm{g}$ in $1 \mathrm{~mL})$ was incubated with various concentrations of urea at room temperature overnight. The Trp emission spectrum was then recorded with excitation wavelength of $295 \mathrm{~nm}$ in ISS K2 spectrofluorometer (ISS, Inc). Stability of protein structure was monitored by red shift of $\lambda \max$ and the attenuation of emission.

\section{RESULTS}

In our initial report, a deletion mutation $\left(\Delta 2 \beta_{2}-2 \beta_{3}\right), 2$ individual point mutations (D425K and F427A), and a double mutation $(\mathrm{K} 397 \mathrm{D}+\mathrm{D} 425 \mathrm{~K})$ were shown in a cell culture assay to confer the DN phenotype on PA (15). The K397D mutation alone did not confer this phenotype, but enhanced the DN effect of the D425K mutation. Three of the DN PAs were tested in the Fischer 344 rat model of anthrax lethal toxin action, and all were shown to be effective in rescuing the animals (15). We have now chosen $4 \mathrm{DN}$ forms of PA to test further: a single mutant (F427K); a double (K397D + D425K); a triple (K397D + D425K + F427A); and a quadruple $\left(\mathrm{K} 397 \mathrm{D}+\mathrm{D} 425 \mathrm{~K}+\mathrm{F} 427 \mathrm{~A}+\Delta 2 \beta_{2}-2 \beta_{3}\right)$. The 4 mutant proteins were expressed in E. coli, purified and tested for selected activities and stability.

We tested the ability of the 4 mutants to bind and translocate radiolabeled LFn across the plasma membrane of CHO-K1 cells in response to a low-pH pulse. $\mathrm{LFn}$ is the $\mathrm{N}$-terminal, $\mathrm{PA}_{63}$-binding domain of LF. We bound trypsin-activated PA to CHO-K1 cells at $4{ }^{\circ} \mathrm{C}$, and then added [ $\left.{ }^{35} \mathrm{~S}\right]-\mathrm{LFn}$. Cell-bound radiolabel was quantified before and after treatment of the cells with buffer of $\mathrm{pH} 4.8$. The mutant PAs bound essentially the same amount of LFn as wild-type PA. All 4 mutant proteins were severely impaired in translocation (Figure 1), and no significant differences in translocation efficiency were seen.

The ability of the mutant PAs to permeabilize the plasma membrane under acidic conditions also was tested. Cells were loaded with ${ }^{86} \mathrm{Rb}$, incubated with trypsin-nicked PA for $1 \mathrm{~h}$ on ice, washed, and then treated with buffer of $\mathrm{pH} 5$ or $\mathrm{pH} 8$. As shown in Figure 2, all of the mutants were severely impaired in release of ${ }^{86} \mathrm{Rb}$ at $\mathrm{pH} 5$, although the F427K mutant showed significantly greater release than the others.

The abilities of the mutant proteins to form heptameric oligomers were examined by gel electrophoresis. When trypsin-nicked PA is incubated with LFn, the ligand promotes oligomerization of the $\mathrm{PA}_{63}$ moiety, and the resulting liganded $\mathrm{PA}_{63}$ heptamer runs as a low-mobility band on polyacrylamide gels under nondenaturing conditions. As shown in Figure 3A, the 4 mutant forms of PA showed no impairment in forming these ligand complexes. Such complexes remain dissociable by SDS if the $\mathrm{pH}$ is maintained above approximately $\mathrm{pH}$ 8. If the medium is acidified however, the heptameric PA63 moiety converts to an SDS resistant form, which has been hypothesized to correspond to the pore form. As shown in Figure $3 \mathrm{~B}$, the double, the triple, and the quadruple mutants were unable to convert to the SDS-resistant form at $\mathrm{pH}$ 5.0. The F427K mutant gave a readily detectable amount of this form however, consistent with its activity in the ${ }^{86} \mathrm{Rb}$ release assay.

To compare their potency as DN inhibitors, we tested each of the mutant proteins for ability to antagonize the inhibition of protein synthesis in CHO-K1 cells by a mixture of wild-type PA and LFn-DTA. LFn-DTA contains LFn fused to DTA, which catalyzes the ADP-ribosylation of elongation factor-2 upon entry into the cytosol. As shown in Figure 4, all 4 mutants almost completely blocked toxin action at a molar ratio $\geq 1$ with respect to wild-type PA. The double and triple mutants were significantly more potent, and the quadruple showed the greatest activity at lower concentrations.

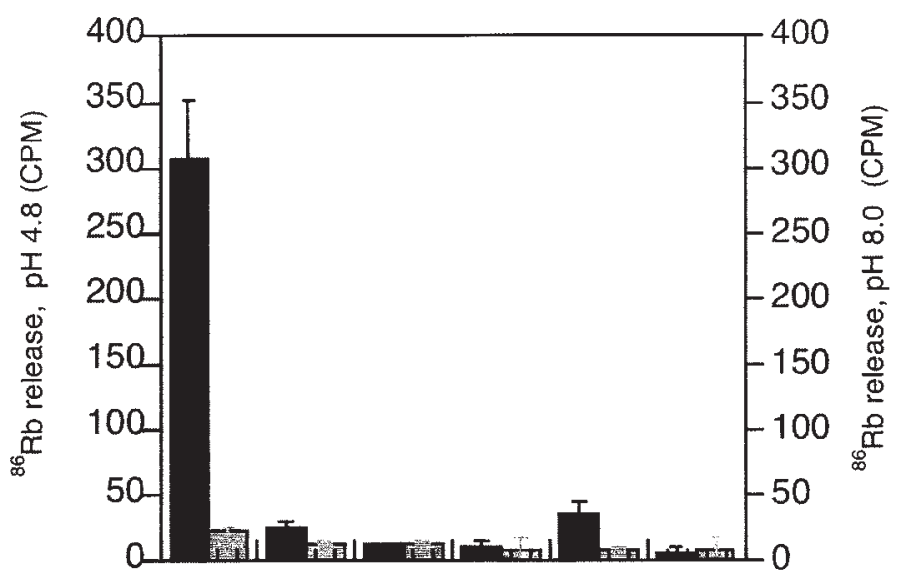

WT Double Triple Quad F427K Control

Figure 2. ${ }^{86} \mathrm{Rb}$ release from $\mathrm{CHO}-\mathrm{K} 1$ cells treated with $\mathrm{DN}$ forms of PA $\mathrm{CHO}-\mathrm{K} 1$ cells preloaded with ${ }^{86} \mathrm{Rb}$ were incubated with nicked PA $(5 \times$ $10^{-8} \mathrm{M}$ ) on ice for $1 \mathrm{~h}$. The cells were then washed with ice-cold PBS and treated with $\mathrm{pH} 4.8$ or $\mathrm{pH} 8.0$ buffer for $15 \mathrm{~min}$ to trigger pore formation. ${ }^{86} \mathrm{Rb}$ released into the supernatant fluid at pH 4.8 ( $\square$ ) or pH 8.0 ( $\square$ ) was measured. 


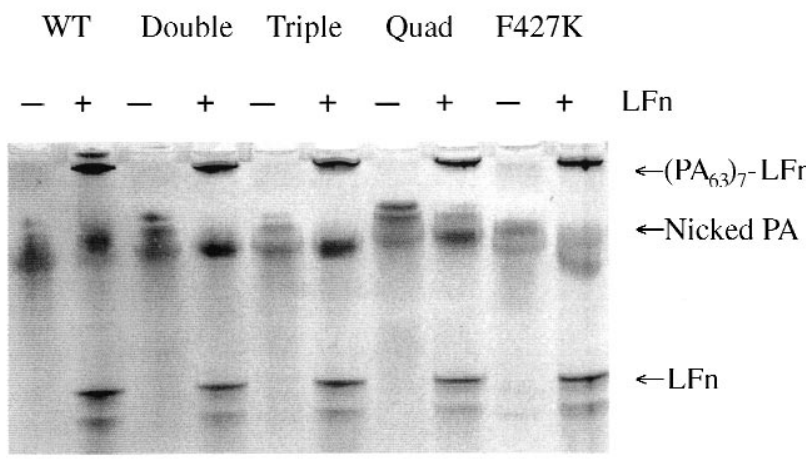

B

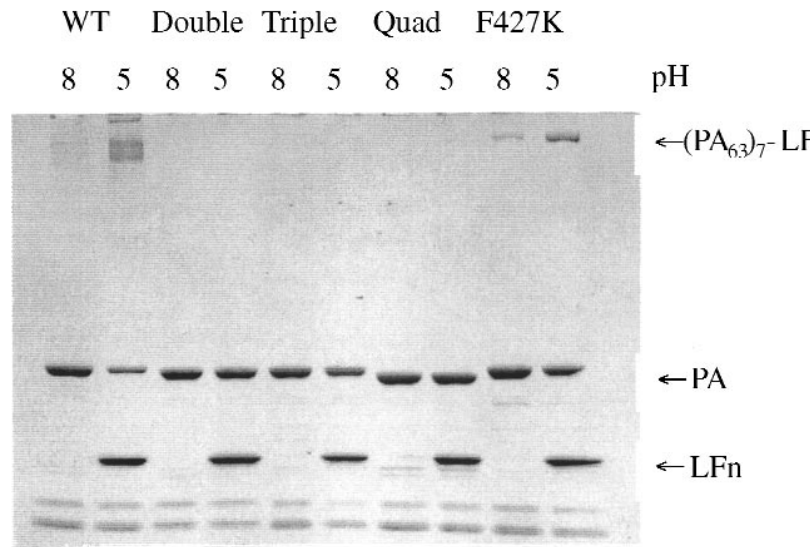

Figure 3. Formation of $\mathrm{LFn}-\left(\mathrm{PA}_{63}\right)_{7}$ complex by DN PA. A: Formation of $\left(\mathrm{PA}_{63}\right)_{7}$-LFn complex was determined by incubating nicked PA with or without an equal molar amount of LFn and incubated at room temperature for $2 \mathrm{~h}$. (PA 63$)_{7}$-LFn complex formation was visualized by $4 \%$ to $20 \%$ native gel electrophoresis. B: Conversion of LFn- $\left(\mathrm{PA}_{63}\right)_{7}$ complex to SDS-resistant form was triggered by adding $100 \mathrm{mM}$ sodium acetate, pH 4.0. After incubation at room temperature for $30 \mathrm{~min}$, samples were loaded on $4 \%$ to $20 \% \mathrm{gel}$ and run on SDS-PAGE. SDS-resistant complex was visualized by Coomassie Brilliant Blue R-250 staining.

The current model of DN action assumes that a DN mutant must co-oligomerize with wild-type PA. This is believed to occur after binding of these forms of PA to their cell-surface receptor. Figure 5 shows that introducing a mutation that inhibits receptor binding (N682S) into the double mutant virtually ablated its DN activity, as predicted. However, introducing the oligomerizationblocking mutation, D512K, into the double did not affect DN activity. The significance of this finding is discussed below.

To test the relative stabilities of the 4 mutant PAs, we examined their unfolding as a function of urea concentration, using intrinsic tryptophan fluorescence as an index of structure perturbation. All of them showed $\lambda \max$ of 327 to $329 \mathrm{~nm}$ in the absence of urea. This value increased to values of $338 \mathrm{~nm}$ or greater as the urea concentration was raised to $2 \mathrm{M}$. As shown in Figure 6, the intensity of emission at the $\lambda \max$ declined to a constant value over this range of concentrations. With the quadruple mutant, the decline occurred at a significantly lower concentration than with the other mutants. The wild-type PA showed the highest resistance to unfolding, and the curves of the other mutants showed slight reductions in stability.

\section{DISCUSSION}

Demonstration that certain mutations within the PA moiety of anthrax toxin convert the protein into a potent inhibitor of toxin action is relevant both to the mechanism of toxin action and to development of new types of therapeutics for anthrax. The existence of such mutations strongly supports the notion that translocation of EF and LF is mediated by a multisubunit (heptameric) form of PA that forms a transmembrane pathway for EF and LF to cross to the cytosol. Introduction of a translocation-defective subunit into the heptamer-perhaps even in single copy - is able to interfere with the membrane-penetration and translocation processes, thereby blocking toxin action.

In the current work we characterized 4 PAs, each with a different set of mutations that show DN properties. In our initial study, the double mutant, K397D + D425K, proved to have slightly more potent DN activity than the D425K, the F427A, or the $\Delta 2 \beta_{2}-2 \beta_{3}$, which in turn were far more potent than the K397D (15). In the current study we used the double as the standard, and combined it with 2 other DN mutations of the original study. The triple contained the double plus the F427A mutation; and the quadruple contained the triple plus the $\Delta 2 \beta_{2}-2 \beta_{3}$. For the 4th mutant we chose the F427K single mutation to determine the effect of converting a strongly apolar side chain to one that is highly polar and positively charged.

Consistent with prior results, the 4 mutant PAs were not impaired in oligomerization, ligand binding, or by implication from the LFn-binding experiment shown in Figure 1, receptor binding. However all were profoundly defective in the $\mathrm{pH}$ dependent functions such as pore formation as assayed by ${ }^{86} \mathrm{Rb}$ release, the related property of conversion of the heptamer to an SDS-resistant conformation under acidic conditions, and translocation of LFn across the CHO-K1 plasma membrane. The F427K mutation was the weakest of the 4 mutants, causing significant

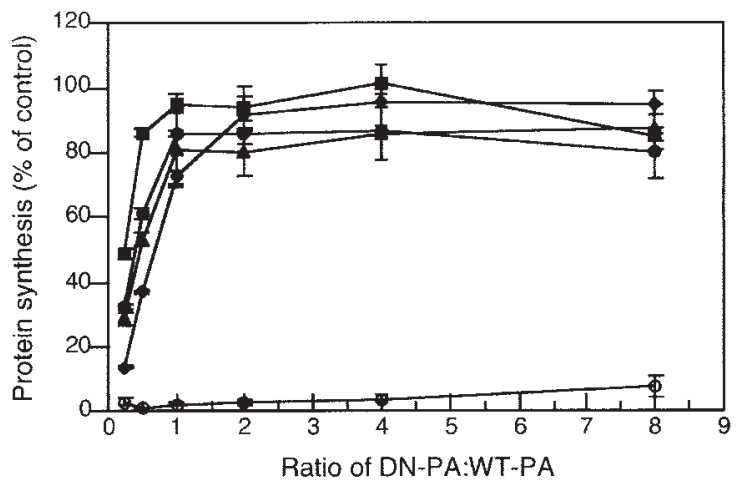

Figure 4. DN activity of various DN forms of PA. PA (WT [O], the double $[\mathbf{0}]$, the triple $[\boldsymbol{\Delta}]$, the quadruple [ $\mathbf{\square}]$, or the F427K mutant $[\boldsymbol{\bullet}]$ ) was mixed with a constant amount of WT PA (200 pM) and LFn-DTA (1 nM) at different ratios (from $0.25: 1$ to $8: 1$, in 2-fold increments) and incubated with $\mathrm{CHO}-\mathrm{K} 1$ cells at $37{ }^{\circ} \mathrm{C}$ for $4 \mathrm{~h}$. The medium was then removed and replaced with leucine-free medium supplemented with $1 \mu \mathrm{Ci} / \mathrm{mL}$ $3 \mathrm{H}$-leucine. After incubation at $37^{\circ} \mathrm{C}$ for $1 \mathrm{~h}$, DN activity was measured by incorporation of ${ }^{3} \mathrm{H}$-leucine into newly synthesized proteins. 


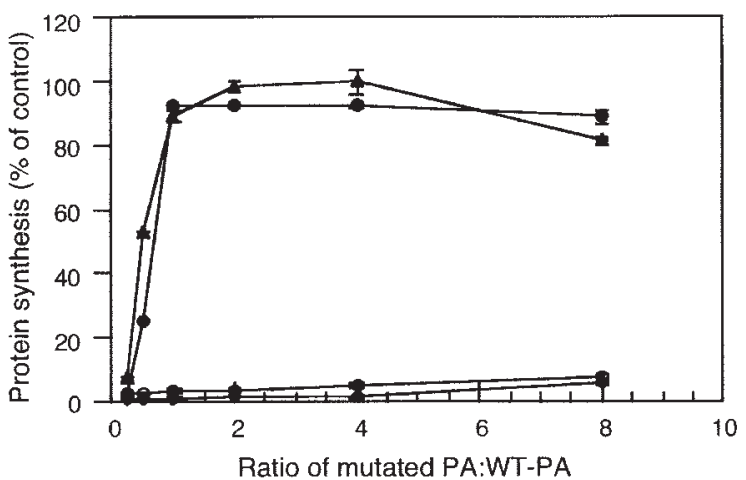

Figure 5. DN activity of oligomerization- and receptor binding-deficient forms of the double mutant. PA (WT [O], the double [0], the double + D512K [ $\mathbf{\Lambda}]$; or the double + N682S [ ] ]) was mixed with constant amount of WT PA (200 pM) and LFn-DTA (1 nM) at various ratios (from 0.25:1 to 8:1, in 2-fold increments) and incubated with $\mathrm{CHO}-\mathrm{Kl}$ cells at $37^{\circ} \mathrm{C}$ for $4 \mathrm{~h}$. The medium was then removed and replaced with leucine-free medium supplemented with $1 \mu \mathrm{Ci} / \mathrm{mL}{ }^{3} \mathrm{H}$-leucine. After incubation at $37^{\circ} \mathrm{C}$ for $1 \mathrm{~h}$, DN activity was measured by incorporation of ${ }^{3} \mathrm{H}$ into newly synthesized proteins.

levels of ${ }^{86} \mathrm{Rb}$ release and formation of some SDS-resistant heptamer under acidic conditions.

Whereas introduction of the F427A mutation into the double caused no enhancement of its DN activity, the $\Delta 2 \beta_{2}-2 \beta_{3}$ mutation appeared to somewhat enhance the DN activity of the double in the low concentration range. This suggests that a single subunit of the double mutant may not be sufficient to inactivate completely an otherwise wild-type heptamer. If this is the case, a high percentage, but not all, of the heptamers containing a single double-mutant subunit may abort under acidic conditions. The DN activity of the F427K mutation was lower than that of the double

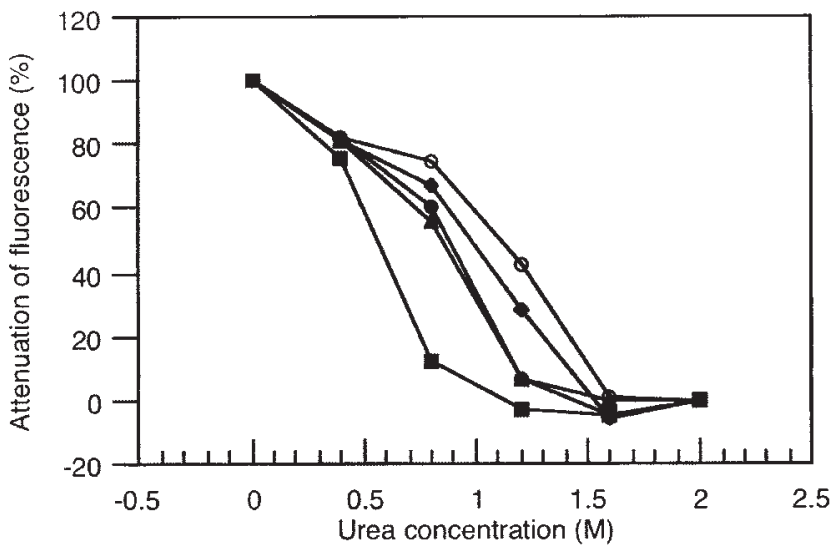

Figure 6. Intrinsic fluorescence of PA at $\lambda$ max as a function of urea concentration. PA (50 $\mu \mathrm{g}$ in $1 \mathrm{~mL}$ ) was incubated with various concentrations of urea overnight. Tryptophan emission spectra (300 nm to $450 \mathrm{~nm}$; 1-nm increments) were recorded with excitation wavelength $295 \mathrm{~nm}$.

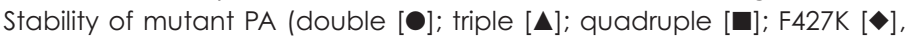
and WT [O]) in urea was monitored by energy attenuation at $\lambda$ max. Energy attenuation was calculated as

$$
\text { Attenuation percent }=\left(A_{i}-A_{2}\right) /\left(A_{0}-A_{2}\right) \times 100 \%
$$

$A_{i}=$ Photon counting at $\lambda$ max of WT or mutant PA with $i$ molar urea concentration. or triple mutant at low concentrations, consistent with its activity levels found in the ${ }^{86} \mathrm{Rb}$ release and SDS-resistant heptamer formation.

The finding that the DN activity of the double mutant is negated by introduction of a 3rd mutation (N682S) that blocks receptor binding is consistent with the notion that DN PA must bind to the PA receptor in order to co-oligomerize with wild-type PA. The finding that introduction into the double mutant of a 3rd mutation, D512K, that effectively blocks oligomerization did not affect DN activity would not necessarily have been predicted but can be readily explained. The D512K mutation would not be expected to block interaction of the double-mutant PA into wildtype oligomers as the opposite oligomerization interface of the mutant PA remains competent. Thus heptamers containing 6 wild-type PA subunits and a single K397D + K425K + D512K would be predicted to form. Only 1 of the 7 subunit:subunit interfaces in such a heteroheptamer would be perturbed, and apparently this structural perturbation is insufficient to affect translocation.

Although the quadruple mutant showed slightly enhanced DN activity relative to the double and triple mutants, the $\Delta 2 \beta_{2}-2 \beta_{3}$ destabilized the protein to a greater degree than the other mutations, as judged by intrinsic fluorescence of the proteins at various urea concentrations. This suggests that the quadruple mutant may also be less stable in vivo, which could compromise its activity as a DN inhibitor of toxin action or an immunogen. However the reductions in stability of the various mutants tested here may be of little or no physiological consequence given that we have seen no indications of instability in our other investigations of these proteins, and the double mutant, the F427A mutant, and the $\Delta 2 \beta_{2}-2 \beta_{3}$ mutant manifested immunogenicity at least equal to that of wild-type PA (15).

The DN forms of PA studied here and elsewhere represent a novel approach to both therapy and prophylaxis against anthrax. Not only do these mutant proteins have potent antitoxic activity, acting at substoichiometric levels with respect to wild-type PA, but also they retain the immunogenic properties of the parent molecule. Thus they may be of particular interest in post-exposure propylaxis, as well as therapy. The results reported here suggest that the double and triple mutants may have the best combination of DN activity and stability for these purposes. The various mutants will need to be tested in vivo to verify this prediction.

\section{ACKNOWLEDGMENTS}

We thank Michael Mourez for help in this work and reading of the manuscript. This work was supported by NIH Grant Al-22021. RJC holds equity in PharmAthene Inc.

Address correspondence and reprint requests to $R$ John Collier, Department of Microbiology and Molecular Genetics, Harvard Medical School, 200 Longwood Avenue, Boston, MA 02115. Phone: 617-432-1930; fax: 617-432-0115; e-mail: jcollier@hms.harvard.edu.

Submitted January 8, 2003; accepted for publication January 15, 2003. 


\section{REFERENCES}

1. Leppla SH. (1991) The anthrax toxin complex. In: Alouf J (ed.) Sourcebook of Bacterial Protein Toxins. Academic Press, New York, pp. 277-302.

2. Mourez M et al. (2002) 2001: a year of major advances in anthrax toxin research. Trends Microbiol. 10:287-93.

3. Klimpel KR, Molloy SS, Thomas G, Leppla SH. (1992) Anthrax toxin protective antigen is activated by a cell surface protease with the sequence specificity and catalytic properties of furin. Proc. Natl. Acad. Sci. U.S.A. 89:10277-81.

4. Gordon VM, Klimpel KR, Arora N, Henderson MA, Leppla SH. (1995) Proteolytic activation of bacterial toxins by eukaryotic cells is performed by furin and by additional cellular proteases. Infect. Immun. 63:82-7.

5. Petosa C, Collier RJ, Klimpel KR, Leppla SH, Liddington RC. (1997) Crystal structure of the anthrax toxin protective antigen. Nature 385:833-8.

6. Milne JC, Furlong D, Hanna PC, Wall JS, Collier RJ. (1994) Anthrax protective antigen forms oligomers during intoxication of mammalian cells. J. Biol. Chem. 269:20607-12.

7. Friedlander AM. (1986) Macrophages are sensitive to anthrax lethal toxin through an acid-dependent process. J. Biol. Chem. 261:7123-6.

8. Blaustein RO, Koehler TM, Collier RJ, Finkelstein A. (1989) Anthrax toxin: channel- forming activity of protective antigen in planar phospholipid bilayers. Proc. Natl. Acad. Sci. U.S.A. 86:2209-13.

9. Leppla SH. (1982) Anthrax toxin edema factor: a bacterial adenylate cyclase that increases cyclic AMP concentrations of eukaryotic cells. Proc. Natl. Acad. Sci. U.S.A. 79:3162-66

10. Duesbery NS et al. (1998) Proteolytic inactivation of MAP-kinase-kinase by anthrax lethal factor. Science 280:734-7.

11. Pellizzari R, Guidi-Rontani C, Vitale G, Mock M, Montecucco C. (1999) Anthrax lethal factor cleaves MKK3 in macrophages and inhibits the LPS/IFN $\gamma$-induced release of NO and TNF $\alpha$. FEBS Lett. 462:199-204.

12. Benson EL, Huynh PD, Finkelstein A, Collier RJ. (1998) Identification of residues lining the anthrax protective antigen channel. Biochemistry 37:3941-8.

13. Sellman BR, Nassi S, Collier RJ. (2001) Point mutations in anthrax protective antigen that block translocation. J. Biol. Chem. 276:8371-6.

14. Miller CJ, Elliott JL, Collier RJ. (1999) Anthrax protective antigen: prepore-to-pore conversion. Biochemistry 38:10432-41.

15. Sellman BR, Mourez M, Collier RJ. (2001) Dominant-negative mutants of a toxin subunit: an approach to therapy of anthrax. Science 292:695-7.

16. Singh Y, Khanna H, Chopra AP, Mehra V. (2001) A dominant negative mutant of Bacillus anthracis protective antigen inhibits anthrax toxin action in vivo. J. Biol. Chem. 276:22090-4. 